\title{
FREQUÊNCIA RELATIVA DE FIMBRIAS DAS AMOSTRAS DE Escherichia coli COLETADAS DE BEZERROS COM DIARREIA NO RECÔNCAVO DA \\ BAHIA
}

\author{
Bruna de Jesus Mamona ${ }^{1}$; Claudio Roberto Nóbrega Amorim²
}

\author{
1. Voluntária de Iniciação Científica, Graduanda em Ciências Biológicas, Universidade Estadual de Feira de Santana, \\ e-mail: bjmamona@gmail.com \\ 2. Orientador, Departamento de Ciências Biológica, Universidade Estadual de Feira de Santana, e-mail: \\ amorim@uefs.com
}

PALAVRAS-CHAVE: Escherichia; Fímbria; Colibacilose.

\section{INTRODUÇÃO}

Escherichia coli é uma bactéria gram-negativa, pertencente à família Enterobacteriaceae, que coloniza o trato intestinal de vertebrados e apresenta como características formato de bastonete, respiração anaeróbia facultativa e tem como temperatura ideal para seu crescimento $37^{\circ} \mathrm{C}$ (Almeida, 2013; Pereira, 2016). Em grande parte, cepas de E. coli estabelecem relação de comensalismo com seu hospedeiro, porém existem cepas patogênicas que causam infecções extraintestinais e infecções intestinais como diarreia e desinteria (Almeida, 2013; Kaper et al., 2004; Nataro \& Kaper, 1998; Pereira et al., 2016). A E. coli pode ser classificada de acordo com os fatores de virulência que apresenta, como por exemplo fímbrias e produção de toxinas, estando estes relacionados a patogenicidade (Almeida, 2013). A Escherichia coli enterotoxigênica (ETEC) está frequentemente associada com a promoção de quadro diarreico em bezerros neonatos, chamado de colibacilose, devido a colonização do trato intestinal a partir de fímbrias e toxinas (Reck, 2009).

As fímbrias são moléculas proteicas localizadas na superfície celular da bactéria que promove a aderência às células epiteliais do hospedeiro (Almeida, 2013). Podem ser classificadas quanto à sua capacidade de aglutinação com hemácias em presença do carboidrato D-manose, quando ocorre a hemaglutinação são chamadas manose resistentes (MR) e quando a hemaglutinação é inibida são chamadas de manose sensíveis (MS) (Almeida, 2013). Os tipos fimbriais comumente relacionados a cepa de ETEC colonizadoras de trato intestinal de bezerros, são: F5 (K99), F17 e F41 (Salvatori et al., 2013). Dessa maneira, o trabalho teve como objetivo identificar os tipos de fimbrias em E. coli isolada das amostras de fezes coletadas de bezerros com diarreia no recôncavo baiano e a partir disso, realizar uma análise de frequência relativa.

\section{MATERIAL E MÉTODOS OU METODOLOGIA}

As análises foram feitas a partir de 25 amostras de fezes de bezerros recémnascidos apresentando diarreia, que foram gentilmente cedidas pelo Professor Joselito Nunes Costa, da Faculdade de Medicina Veterinária da Universidade Federal do Recôncavo Baiano, no laboratório de Microbiologia Aplicada a Saúde (LAMASP) da Universidade Estadual de Feira de Santana (UEFS). Para o isolamento de Escherichia coli, as amostras foram diluídas em meio tamponado $\mathrm{pH} 7,4$, esterilizado, e semeadas em meio de cultura Agar MacConkey por $24 \mathrm{~h}$ a $37^{\circ} \mathrm{C}$. As colônias indicativas de 
fermentadoras de lactose, foram inoculadas em caldo $\mathrm{BHI}$ por $24 \mathrm{~h}$ a $37^{\circ} \mathrm{C}$ e posteriormente inoculada em caldo EC com tudo de Durham invertido, por $24 \mathrm{~h} \mathrm{a} 45^{\circ} \mathrm{C}$ em banho-maria. As amostras que apresentaram turbidez no caldo e produção de gás no tubo de Durham, foram semeadas no Agar Eosina-Azul de Metileno (EMB) com incubação de $24 \mathrm{~h}$ a $48 \mathrm{~h}$ em temperatura de $35^{\circ} \mathrm{C}$. Após esse período, as colônias que apresentaram crescimento com coloração verde metálica, seguiram para identificação bioquímica.

As provas bioquímicas consistiram em: produção de indol, prova do vermelho de metila (VM), prova de Voges-Proskauer (VP), utilização do citrato, descarboxilação da lisina, produção de sulfeto de hidrogênio e prova da motilidade (Koneman, 2001).

Para a identificação genética das fímbrias, inicialmente foram realizados dois métodos de extração de DNA das amostras estudadas e das amostras padrão para as fimbrias F17, F5 e F41 (controle positivo), proposto por Blanco et al. (1993) e pelo Canadian Center for Barcoding, ambos com modificações.

As tentativas para detecção e identificação das fímbrias foram feitas por meio de PCR utilizando-se primers específicos para cada tipo fimbrial e por fim, a aplicação do produto da PCR foi feita em gel de agarose $2 \%$ (eletroforese) com tampão TBE (1X) a 100V por 40minutos, utilizando o GelRed, corante para ácidos nucleicos, para leitura. As diversas formas de tentativas de adequação da bioquímica da PCR para a obtenção de resultados confiáveis, consistiram em: concentração do DNA extraído - sem diluição e diluído a 200ng/ $\mu 1,100 \mathrm{ng} / \mu 1,50 \mathrm{ng} / \mu 1$ e 1:10; alteração da Taq DNA polimerase - Taq DNA polimerase comum ou Top-Taq DNA polimerase; quantidade de primer utilizado - $2 \mu \mathrm{l}$ ou $1 \mu \mathrm{l}$; quantidade de Taq DNA polimerase $(2,5 \mathrm{U})$ utilizada - $0,5 \mu \mathrm{l}$ ou $0,3 \mu \mathrm{l}$; alteração dos reagentes utilizados - dnTP, solução trabalho do primer e $\mathrm{H}_{2} \mathrm{O}$; PCR realizada com gradiente de temperatura; quantidade DNA utilizado - $1 \mu 1$ e $0,5 \mu 1$; extração de DNA refeita.

Essas modificações foram realizadas em cima do protocolo proposto por Clermont et al. (2000), onde as quantidades de reagentes para a PCR são indicadas, para uma solução total de $20 \mu \mathrm{l}$, como sendo: $2 \mu \mathrm{l}$ de buffer (10x), $0,8 \mu \mathrm{l}$ de $\mathrm{MgCl}_{2}(50 \mathrm{mM}), 2 \mu 1$ de primer $1(20 \mathrm{pMol}), 2 \mu 1$ de primer $2(20 \mathrm{pMol}), 0,5 \mu 1$ de Taq DNA polimerase $(2,5 \mathrm{U})$, $1 \mu l$ de dNTP, $1 \mu l$ de DNA (200ng/ $\mu$ l) e água q.s.p (para completar o volume final). No entanto, a solução final foi ajustada para $25 \mu 1$ adicionando-se somente mais água. $\mathrm{O}$ programa para o termociclador consistiu em um estágio inicial de 5 minutos a $94^{\circ} \mathrm{C} ; 30$ ciclos de desnaturação a $94^{\circ}$ por 30 segundos, mais anelamento por 30 segundos com a temperatura ideal para cada primer $\left(56^{\circ} \mathrm{C}\right.$ para $\mathrm{F} 41,60^{\circ} \mathrm{C}$ para $\mathrm{F} 5$ e $65^{\circ}$ para $\left.\mathrm{F} 17\right) \mathrm{e}$ extensão a $72^{\circ} \mathrm{C}$ por 30 segundos; e finalizando com uma extensão final de 7 minutos a $72^{\circ} \mathrm{C}$.

\section{RESULTADOS ALCANÇADOS E DISCUSSÃO}

A semeadura das amostras no Agar MacConkey mostrou crescimento de colônias fermentadores de lactose, característica conferida a Escherichia coli e, portanto, indicando a possibilidade de as amostras serem de E. coli. As colônias fermentadoras de lactose que foram inoculadas no caldo EC apresentaram crescimento e produção de gás no tubo de durhan, sendo mais um indicativo de E. coli. As colônias crescidas no caldo EC apresentaram crescimento de colônias verdes metálicas ao serem semeadas no Agar Eosina-Azul e Metileno (EMB), resultado que indica que se tratava de uma bactéria gram-negativa. Os resultados dos testes bioquímicos corroboraram que as amostras de fato eram de Escherichia coli, apresentando resultados positivos para os testes VM (vermelho de metila), produção de indol e descarboxilação da lisina e resultados negativos para os testes VP (Voges-Proskauer), produção de sulfeto de hidrogênio, 
utilização do citrato e motilidade. Segundo Fortes (2010) o teste de motilidade pode apresentar tanto resultado negativo quanto positivo, pois a locomoção é uma característica variável nas cepas de $E$. coli, no entanto, todas a amostras testadas não apresentaram locomoção, indicando a falta de flagelos locomotores.

A primeira PCR realizada para a detecção da fímbria F41 com 20 amostras escolhidas aleatoriamente mais a amostra padrão, utilizando-se $1 \mu 1$ de DNA (100ng/ $\mu \mathrm{l})$ indicou bandas de tamanho em torno de 100pb (tendo o ladder como referência) em todos os poços, inclusive no controle negativo. Como a bandas que apareceram possuíam em torno de $100 \mathrm{pb}$, era um indicativo de que o gene não foi amplificado visto que o produto esperado para F41 tem em torno de 431pb e o fato de aparecer banda no controle negativo, poderia indicar uma possível contaminação das amostras durante a realização da solução dos reagentes para a PCR, algo relativamente difícil tendo em vista que para isso a contaminação teria que ser por Escherichia coli com região genômica específica para o primer utilizado para uma fímbria que aparece comumente em bezerros. Uma outra possibilidade, seria amplificação do próprio primer ou a falta de anelamento que, como consequência concentrou todo o primer no final da corrida.

A PCR realizada para a fímbria F5 com oito amostras mais a amostra padrão, com a utilização de $1 \mu \mathrm{l}$ de DNA $(100 \mathrm{ng} / \mu \mathrm{l})$, resultou no mesmo que a PCR anterior para a fímbria F41. No entanto, apareceram duas bandas próximas em algumas amostras, um indicativo de dímero de primer, que pode ocorrer quando uma molécula de primer anela com a outra.

Uma nova PCR para eliminação da hipótese de contaminação durante o preparo do mix de PCR foi realizada com poucas amostras e com primers para F41, tomando medidas como utilização de água nova ultrapura, construção do mix na câmara de exaustão e troca de todas a ponteiras durante a pipetagem das amostras do gel de eletroforese. Os resultados obtidos foram iguais as reações em cadeia da polimerase anteriores, indicado que o problema não estava numa possível contaminação.

Outra PCR foi efetuada para os três genes, F5, F41 e F17, utilizando a amostra padrão mais duas amostras aleatórias e o termociclador com gradiente de temperatura variando as colunas $5^{\circ} \mathrm{C}$ em $5^{\circ} \mathrm{C}$ em torno do valor central de $60^{\circ} \mathrm{C}$. Foram confeccionados 6 mixes diferentes, variando concentração de DNA e quantidade de primers e taq DNA polimerase utilizadas. Os resultados foram os mesmos das tentativas anteriores indicando que possivelmente o problema estaria nas extrações realizadas. Neste método, quatro variáveis foram alteradas, temperatura, DNA, primer e taq DNA polimerase, o esperado seria que pelo menos em uma das amostras padrões aparecesse a banda de acordo com o produto esperado e em cima desse resultado, analisar a mudança na bioquímica que proporcionou o correto anelamento e trabalha-lo para aplicar nas outras amostras e a partir disso, identificar as fímbrias. Novas extrações foram realizadas e a extração com método de fervura, apontou que continha boa quantidade de DNA íntegro para a realização da PCR, devido a visualização de bandas com incidência mais forte próximo ao poço do gel, o que indica maior tamanho, e menos arrasto de material em comparação com o outro método, resultado de menor fragmentação de material genético.

A PCR para o gene F5 realizada com os métodos de extração refeitos, utilizando a amostra padrão e duas amostras aleatórias, proporcionou como resultado o surgimento de bandas na amostra padrão. Porém, o esperado seria aparecer apenas uma banda, o surgimento de três bandas revela que há uma inespecificidade do primer em relação a região alvo, este problema pode ser resultante da temperatura utilizada para anelamento e uma correção poderia ser o aumento dessa temperatura. 


\section{CONSIDERAÇÕES FINAIS}

De acordo com os resultados que foram possíveis obter, nas amostras coletadas de fezes diarreicas de bezerros neonatos haviam cepas de Escherichia coli. Com relação a realização para a identificação das fímbrias, o principal problema resultante da não amplificação, residia em como foi conduzida a de extração de DNA. Diante disso, se faz necessário dar continuidade ao estudo, adequando o processo da PCR, para a identificação dessas cepas a partir de seus fatores de virulência, de modo que se obtenha um maior conhecimento acerca dessas estirpes que causaram a enfermidade nestes animais.

\section{REFERÊNCIAS}

ALMEIDA, A. M. S. 2013. Características biológicas e antigênicas de Escherichia coli com ênfase aos genes de virulência. Dissertação (Mestrado em Ciência Animal). Escola de Veterinária e Zootecnia, Universidade Federal de Goiás. Goiânia.

BLANCO, J. \& BLANCO, M. Escherichia coli enterotoxigénicos, necrotoxigénicos verotoxigénicos de origem humano y bovino, patogénesis, epidemiología $y$ diagnóstico microbiologico. In Servicio Pub. Diputacion Provincial, Lugo, Espanha. 1993.

FORTES, F. B. B. Perfil Bioquímico de amostras de Escherichia coli isoladas de materiais avícolas no Estado do Rio Grande do Sul e sua relação com a patogenicidade. Dissertação (Mestrado em Ciências Veterinárias). Universidade Federal do Rio Grande do Sul. 2008.

KAPER, J. B.; NATARO, J. P. \& MOBLEY, H. L. T. 2004. Pathogenic Escherichia coli.Nature Reviews 2: 123-140.

KOnEMAN, E.W. et al. Diagnóstico Microbiológico: Texto e Atlas Colorido. 5. ed. Rio de Janeiro: MEDSI, 2001. p.1465.

NATARO, J. P. \& KAPER, J. B. 1998. Diarrheagenic Escherichia coli. Clinical Microbiology Reviews 11(1): 142-201.

PEREIRA, D. A. et al. 2016. Virulence factors of Escherichia coli in relation to the importance of vaccination in pigs. Ciência Rural 46(8): 1430-1437.

RECK, M. V. M. 2009. Diarréia neonatal bovina. Monografia (Graduação) Universidade Federal do Rio Grande do Sul, Faculdade de Veterinária. Porto Alegre.

SALVADORI, M. R. et al. 2003. Virulence factors of Escherichia coli isolated from calves with diarrhea in Brazil. Brazilian Journal of Microbiology 34: 230-235. 